\title{
Duas novas espécies de Leandra Raddi (Melastomataceae) para o Estado de São Paulo, Brasil
}

\author{
José Fernando A. Baumgratz ${ }^{1,3}$ e Maria Leonor D’El Rei Souza ${ }^{2}$
}

Recebido em 14/05/2003. Aceito em 02/02/2005

\begin{abstract}
RESUMO - (Duas novas espécies de Leandra Raddi (Melastomataceae) para o Estado de São Paulo, Brasil). São descritas e ilustradas duas novas espécies de Leandra para a flora do Estado de São Paulo - L. truncata Baumgratz \& D'El Rei Souza e L. mattosii Baumgratz \& D'El Rei Souza, pertencentes à seção Oxymeris (DC.) Cogn. Para estas, comentam-se, também, as diferenças morfológicas em relação às espécies mais afins.
\end{abstract}

Palavras-chave: Leandra seção Oxymeris, Melastomataceae, taxonomia, São Paulo, Brasil

ABSTRACT - (Two new species of Leandra Raddi (Melastomataceae) from São Paulo State, Brazil). Two new species of Leandra from São Paulo are described and illustrated - L. truncata Baumgratz \& D’El Rei Souza and L. mattosii Baumgratz \& D'El Rei Souza. These species belong to the section Oxymeris (DC.) Cogn. and a comparison with related species is presented.

Key words : Leandra section Oxymeris, Melastomataceae, taxonomy, São Paulo State, Brazil

\section{Introdução}

As Melastomataceae, incluindo Memecylaceae, constituem uma família pantropical e subtropical, com mais de 4.500 espécies, floristicamente abundante e diversificada na América do Sul. No Brasil, encontram-se cerca de 1.500 espécies, tropicais e subtropicais, distribuídas em 66 gêneros.

Leandra, um gênero neotropical, está constituído por cerca de 200 espécies, que se distribuem desde o México e Antilhas até o sul do Brasil e Argentina. Os últimos estudos revisionais ou abrangentes sobre este gênero para o Brasil e o mundo datam do século XIX (Cogniaux 1886; 1891), sendo, portanto, comum deparar-se com problemas taxonômicos durante a identificação de exemplares. Não é raro encontrar amostras deste gênero indeterminadas ou identificadas duvidosamente, ou até mesmo erroneamente como espécies de outros gêneros, como por exemplo, Miconia Ruiz \& Pav. e Ossaea DC. (Judd \& Skean 1991; M.L.D.R. Souza, dados não publicados; Wurdack 1962).

O gênero Leandra está estreitamente relacionado com Clidemia D.Don, Miconia e Ossaea, e caracteriza-se, principalmente, pelo conjunto dos seguintes caracteres: inflorescências terminais e/ou pseudo-axilares, botões florais de ápice agudo a acuminado, pétalas atenuado-acuminadas a atenuadoagudas e frutos carnosos, do tipo bacídio (Baumgratz 1985), polispérmicos.

O estudo taxonômico do gênero Leandra para a Flora Fanerogâmica do Estado de São Paulo (Souza \& Baumgratz, dados não publicados) proporcionou aos autores uma revisão de vários táxons, evidenciando alguns complexos de espécies afins, com circunscrições taxonômicas pouco consistentes. A revisão da literatura e a análise morfológica de numeroso material, inclusive de exemplares-tipo destes táxons, possibilitaram identificar novas espécies para a Ciência, algumas endêmicas deste Estado e descritas no presente estudo.

\section{Material e métodos}

Os dados apresentados resultam de uma revisão bibliográfica e estudo das coleções de Leandra disponíveis nos Herbários ESA, ESAL, FLOR, FUEL,

\footnotetext{
1 Instituto de Pesquisas Jardim Botânico do Rio de Janeiro, Programa Diversidade Taxonômica, Rua Pacheco Leão 915, CEP 22460-030, Rio de Janeiro, RJ, Brasil

2 Universidade Federal de Santa Catarina, CCB, Departamento de Botânica, Campus Universitário, Trindade, Horto Botânico, C. Postal 476, CEP 88040-900, Florianópolis, SC, Brasil (delrei@ccb.ufsc.br)

3 Autor para correspondência: jbaumgra@jbrj.gov.br
} 
GUA, HB, HBR, HRCB, PMSP, MBM, SP, SPF, SPSF, $\mathrm{R}, \mathrm{RB}$ e UEC, além da análise de fotografias de tipos pertencentes ao F, FI, K, RB, US.

\section{Resultados e discussão}

Leandra truncata Baumgratz \& D'El Rei Souza, sp. nov.

Tipo: Brasil, São Paulo, Campos do Jordão, 5-20/II/1937, fl., P. Campos Porto 3175 (Holótipo RB; Isótipos - HB, US).

Fig. 1.

Nome vulgar: jacatirão-miúdo (M. Koscinski s.n.)

Etimologia: o epíteto específico truncata é em alusão à forma truncada do ápice do cálice, que apresenta as lacínias muito reduzidas.

Species haec morphologia foliorum et inflorescentiarum cum $L$. barbinervis et $L$. quinquedentata optime congruens, sed differt indumento glanduloso-granuloso nunquam stellatofurfuraceo, calyce truncato-undulato ca. $0,5 \mathrm{~mm}$ longo cum tubo et laciniis obsoletis, laciniis exterioribus 0,06-0,35×0,1-0,15 $\mathrm{mm}$, denticulis acuminatis reductis et interioribus oblatis 0,15 $0,4 \times 0,35-0,45 \mathrm{~mm}$.

Arbustos ou arvoretas 1,5-2,5 m alt.; indumento dos ramos, folhas, inflorescências, brácteas, bractéolas, hipanto e cálice esparsa a densamente glandulosogranuloso, tricomas caducos. Pecíolo $(0,6) 1,6-3,7 \mathrm{~cm}$ compr.; lâmina (6)8,3-16,5×(1,8)2,4-6,2 cm, membranácea a papirácea, elíptica, raro ovada, base cuneada a aguda, às vezes decorrente, margem serruladociliolada, às vezes revoluta, ápice agudo a acuminado, face abaxial também esparsamente setulosa ou setuloso-glandulosa na base das nervuras acródromas, cabeça glandular caduca; 5 nervuras acródromas (1)3-17 mm suprabasais, as marginais tênues. Tirsóides 4,5-17 cm compr., terminais, sésseis ou pedunculados; pedúnculo 0,6-5 cm compr.; brácteas 1,5-4×0,3-0,4 mm, bractéolas $0,3-1,3 \times 0,1-0,3 \mathrm{~mm}$, ambas geralmente persistentes, oblongas ou triangulares, agudas. Flores 5-meras; pedicelo 0,2-0,3 $\mathrm{mm}$ compr.; hipanto 1,5-2,5×1,5-2,5 mm, campanulado, às vezes infundibuliforme; zona do disco setulosa; cálice ca. $0,5 \mathrm{~mm}$ compr., truncado-ondulado, com tubo e lacínias obsoletos, lacínias bilobadas, as externas $0,06-0,35 \times 0,1-0,15 \mathrm{~mm}$, reduzidas a dentículos acuminados, as internas 0,15-0,4×0,35-0,45 mm, oblatas, ápice amplamente arredondado; pétalas 2,5-2,7×1-1,3 mm, alvas, reflexas, triangulares ou triangular-deltóides, acuminadas, glabras ou raros tricomas glandulosos na face adaxial; estames isomorfos, subiguais em tamanho, ou dimorfos, de dois tamanhos, filetes maiores 1,9-2,5 mm compr., menores 1,7-2,3 mm compr., anteras alvas, maiores 1,7-2,1 mm compr., menores 1,3-1,8 mm compr., obovadas ou oblongas, base cuneada, extrorsamente curvas, poro terminal ou terminal-dorsal, conectivo geralmente espessado no dorso, 0,2-0,3 mm prolongado abaixo das tecas, inapendiculado ou apêndice dorsal obsoleto; ovário 1/2-2/3-ínfero, 1,6-2×1-1,2 mm, com prolongamento apical, 3-locular, glabro; estilete 4,8-7 mm compr., glabro, estigma capitado. Bacídios ca. $5 \times 4 \mathrm{~mm}$, roxo-nigrescentes, oblongos a elípticos; sementes $0,7-1,1 \times 0,5-0,7 \mathrm{~mm}$, geralmente obtriangulares, às vezes oblongas ou obovadas, testa levemente granulada.

Parátipos: BRASIL. São Paulo: Campos do Jordão, 4/II/1992, fl., A. Amaral et al. 26 (SPSF); 8/II/1980, fl., R.A.A. Barreto 56 (HRB, RB); 24/IV/1981, fr., R.A.A. Barreto 239 (HRB, RB, SPSF); 27/IV/1981, fr., R.A.A. Barreto 251 (HRB, RB); 5-20/II/1937, fl. fr., P. Campos Porto 3173 (R, RB); 5-20/II/1937, fl. fr., P. Campos Porto 3255 (RB); 28/III/1994, fr., I. Cordeiro et al. 1306 (ESA, HRCB, SP, SPF, UEC); s.d., fl. fr., M. Koscinski s.n. (SPSF 6501); II/1935, fl., M. Kuhlmann s.n. (SPF 83491); IV/1945, fl. fr., J.E. Leite 3451 (RB); 16/II/1981, fr., Messias 53, 55 (HRB, RB); 19/I/1987, fl., M.J. Robim 433 (MBM, SP, SPSF); 20/IV/1989, fr., M.J. Robim 627 (MBM, SP SPSF); 24/I/1991, fr., M.J. Robim et al. 670 (SP, SPSF); 20/I/1992, fl., S. Xavier \& E. Caetano 268 (MBM, SP, SPSF).

Espécie endêmica do Estado de São Paulo, restrita ao município de Campos do Jordão, onde ocorre entre 1.800 e 1.900 m.s.m., em formações de floresta ombrófila, mata nebular, campos de altitude e matas com araucária. Coletada com flores e frutos de janeiro a abril.

Leandra truncata enquadra-se na seção Oxymeris, com base na classificação de Cogniaux (1886; 1891), principalmente pelos ramos desprovidos de tricomas hirsutos, pelas inflorescências terminais, não glomeriformes nem secundifloras, brácteas pequenas e hipanto campanulado, não constrito, com indumento glanduloso-granuloso, desprovido de tricomas setosos ou hirsutos. Em relação ao androceu, observa-se que num mesmo espécime podem ser encontradas apenas flores com estames isomorfos ou flores com estames isomorfos e outras com estames dimorfos. Este tipo de flor é o menos freqüente e o dimorfismo estaminal não está associado estritamente às sépalas 


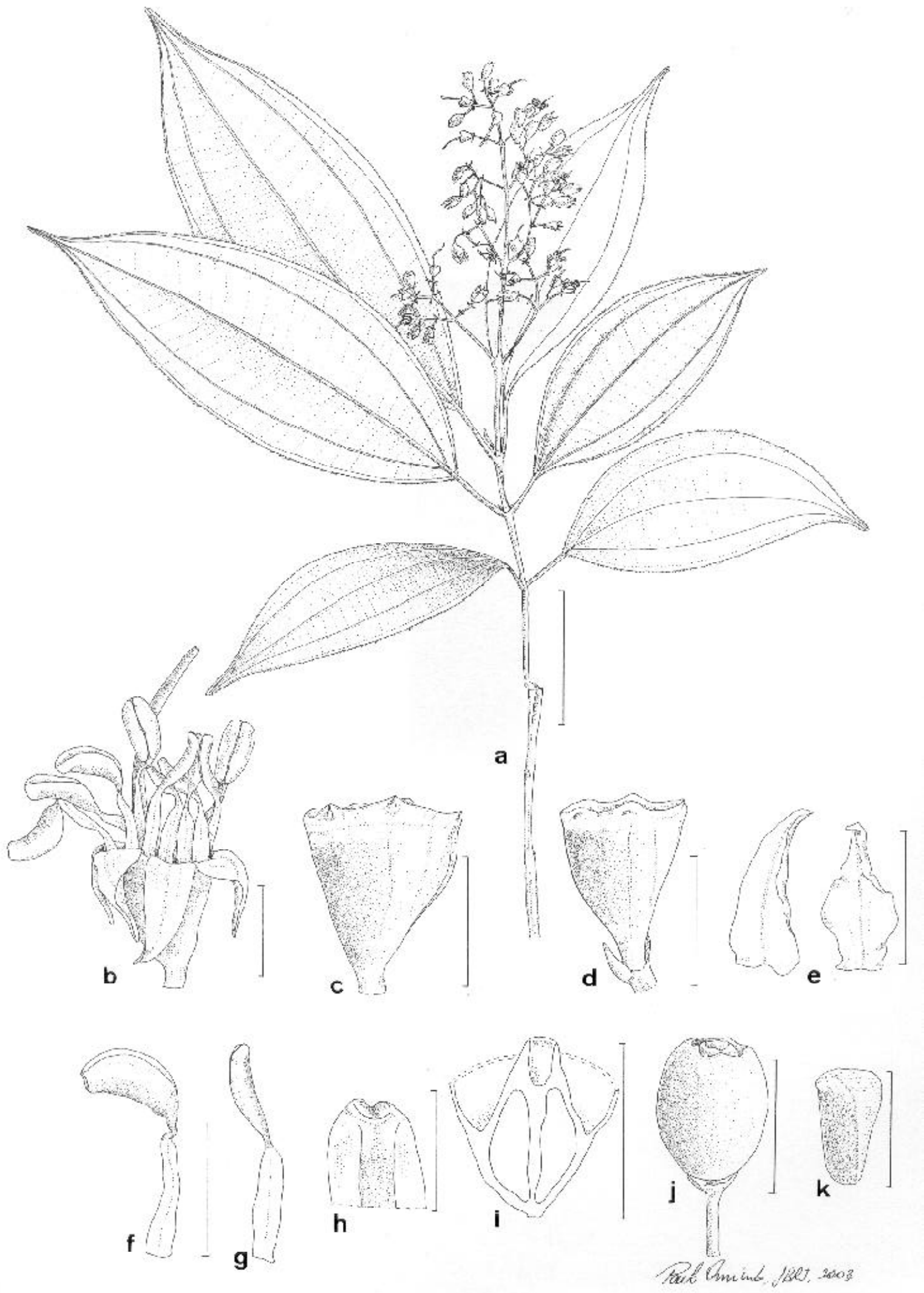

Figura 1. Leandra truncata Baumgratz \& D'El Rei Souza (P. Campos Porto 3175; fruto e semente: R.A.A. Barreto 251): a. Detalhe do ramo florífero. b. Flor. c-d. Pedicelo, hipanto e cálice; detalhe da bractéola na base (d). e. Pétalas. f. Estame maior. g. Estame menor; h. Detalhe do ápice da antera, em vista ventral, com o poro terminal. i. Secção longitudinal do ovário, evidenciando a adnação parcial ao hipanto, lóculos e o prolongamento apical. j. Fruto. k. Semente. (Escalas: a $=3 \mathrm{~cm}, \mathrm{~b}-\mathrm{g}, \mathrm{i}=2 \mathrm{~mm}, \mathrm{~h}, \mathrm{k}=1 \mathrm{~mm}, \mathrm{j}=5 \mathrm{~mm}$ ) 
nem às pétalas, podendo os estames menores ser antesépalos e antepétalos numa mesma flor.

Esta espécie assemelha-se à Leandra barbinervis (Triana) Cogn. e L. quinquedentata (DC.) Cogn., principalmente por apresentar indumento glanduloso-granuloso e pela morfologia da lâmina foliar e inflorescências. Entretanto, estas espécies diferem, particularmente, pelo indumento dos ramos, folhas e inflorescências também furfuráceo-estrelado, cálice nunca truncado-ondulado, com as lacínias externas oblongas a triangulares, subcilíndricas, gibosas, geralmente geniculadas, apiculadas.

Leandra mattosii Baumgratz \& D'El Rei Souza, $s p$. nov.

Tipo: Brasil, São Paulo, Salesópolis, Estação Biológica da Boracéia, perto do rio Coruja, 29/XI/1966, fl. fr., J. Mattos \& N. Mattos 14260 (Holótipo - SP).

Fig. 2.

Species nova praesertim morphologia foliorum et inflorescentiarum cum L. barbinervis, $L$. quinquedentata et L. truncata optime congruens, sed calycis laciniis bilobatis, unilobatis videtur, interioribus 0,2-0,3 $\mathrm{mm}$ longis, exterioribus 0,4-0,6× 0,1-0,2 mm, oblongo-linearibus et subteretibus, non giboso-geniculatis nec apiculatis, partim adnatis apiceque libero recedit. Species nova cum L. truncata affinis etiam indumento stellatofurfuraceo desunt.

Subarbustos a arbustos até ca. $1 \mathrm{~m}$ alt.; indumento dos ramos, pecíolos, face abaxial da lâmina foliar, inflorescências, brácteas e bractéolas, hipanto e cálice moderada a densamente glanduloso-granuloso. Pecíolo 1,6-3,5 cm compr., também viloso; lâmina foliar 6,8-12,6×2,8-5 cm, membranácea, elíptica ou ovada, base obtusa, margem serrulado-ciliolada, às vezes revoluta, ápice atenuado-acuminado, face adaxial moderadamente glanduloso-granulosa, tricomas caducos ou não, abaxial também esparsa a moderadamente viloso-setosa nas nervuras acródromas, tricomas caducos ou não; 5 nervuras acródromas 1-6 mm suprabasais; domácias em tufos de pêlos às vezes presentes. Tirsóides 7-11,5 cm compr., terminais; pedúnculo 1,4-3,5 cm compr.; brácteas 1,5-12×0,2-1,1 mm, bractéolas 1-1,3×0,1-0,2 mm, ambas persistentes, oblongas ou obovadas, agudas a acuminadas. Flores 5-meras; pedicelo 0,6-1 mm compr.; hipanto 1,7-2,1×1,4-2,1 mm, campanulado, inconspicuamente 5-costado; zona do disco glabra; cálice com tubo ca. 0,1 mm compr., lacínias persistentes, eretas, bilobadas, aparentemente unilobadas pelas lacínias internas obscuras, as externas 0,4-0,6×0,1-0,2 mm, oblongo-lineares, agudoacuminadas, subcilíndricas, as internas $0,2-0,3 \mathrm{~mm}$ compr., quase que totalmente adnatas às externas, com apenas sua extremidade apical individualizada; pétalas 1,7-2,7×1-1,4 mm, reflexas, triangular-deltóides, acuminadas, glabras ou tricomas glandulares esparsos na face adaxial; estames isomorfos, filetes $1-1,4 \mathrm{~mm}$ compr., anteras 1-1,4 mm compr., elípticas a obovadas, poro terminal, conectivo $0,2-0,3 \mathrm{~mm}$ prolongado abaixo das tecas, inapendiculado; ovário 1/2-2/3-ínfero, 1,3-2×1,1-1,4 mm, com prolongamento apical, 3-locular, glabro; estilete 4-5 mm compr., glabro, estigma capitado. Fruto maduro não visto.

Etimologia: o epíteto específico mattosii é em homenagem ao engenheiro agrônomo João Rodrigues de Mattos, por sua dedicação à Botânica Sistemática, em particular da família Myrtaceae, durante suas atividades no Instituto de Botânica de São Paulo e, posteriormente, na Secretaria de Agricultura do Estado do Rio Grande do Sul.

Parátipos: BRASIL. São Paulo: Salesópolis, Boracéia, alt. 850 m, 27/XI/1948, fl. fr., M. Kuhlmann 1725 (SP); idem, cabeceira do rio Claro, 16/X/1963, fl., M. Kuhlmann 5036 (SP).

Os poucos espécimes identificados foram coletados apenas no Estado de São Paulo e restritos ao município de Salesópolis, onde ocorrem em torno de $850 \mathrm{~m}$ de altitude, em bordas de matas pluviais e capoeiras, próximos a cursos de rios.

À semelhança do observado em Leandra truncata, L. mattosii também se enquadra na seção Oxymeris, com base em Cogniaux (1886; 1891), principalmente pelo tipo de indumento da planta, posição e tipo das inflorescências, brácteas pequenas e tipo de indumento e forma do hipanto. Nesta espécie, as lacínias do cálice parecem ser unilobadas, pois a lacínia interna é tão reduzida em tamanho e adpressa à externa, que fica totalmente obscurecida na estrutura, estando apenas a extremidade apical individualizada.

Espécie muito semelhante à Leandra barbinervis, L. quinquedentata e $L$. truncata pela morfologia da lâmina foliar e inflorescências, além de compartilhar com L. truncata o indumento apenas do tipo glanduloso-granuloso. Entretanto, L. barbinervis e L. quinquedentata diferem de L. mattosii, particularmente, pelo indumento dos ramos, folhas e inflorescências também furfuráceo-estrelado e cálice nitida- 


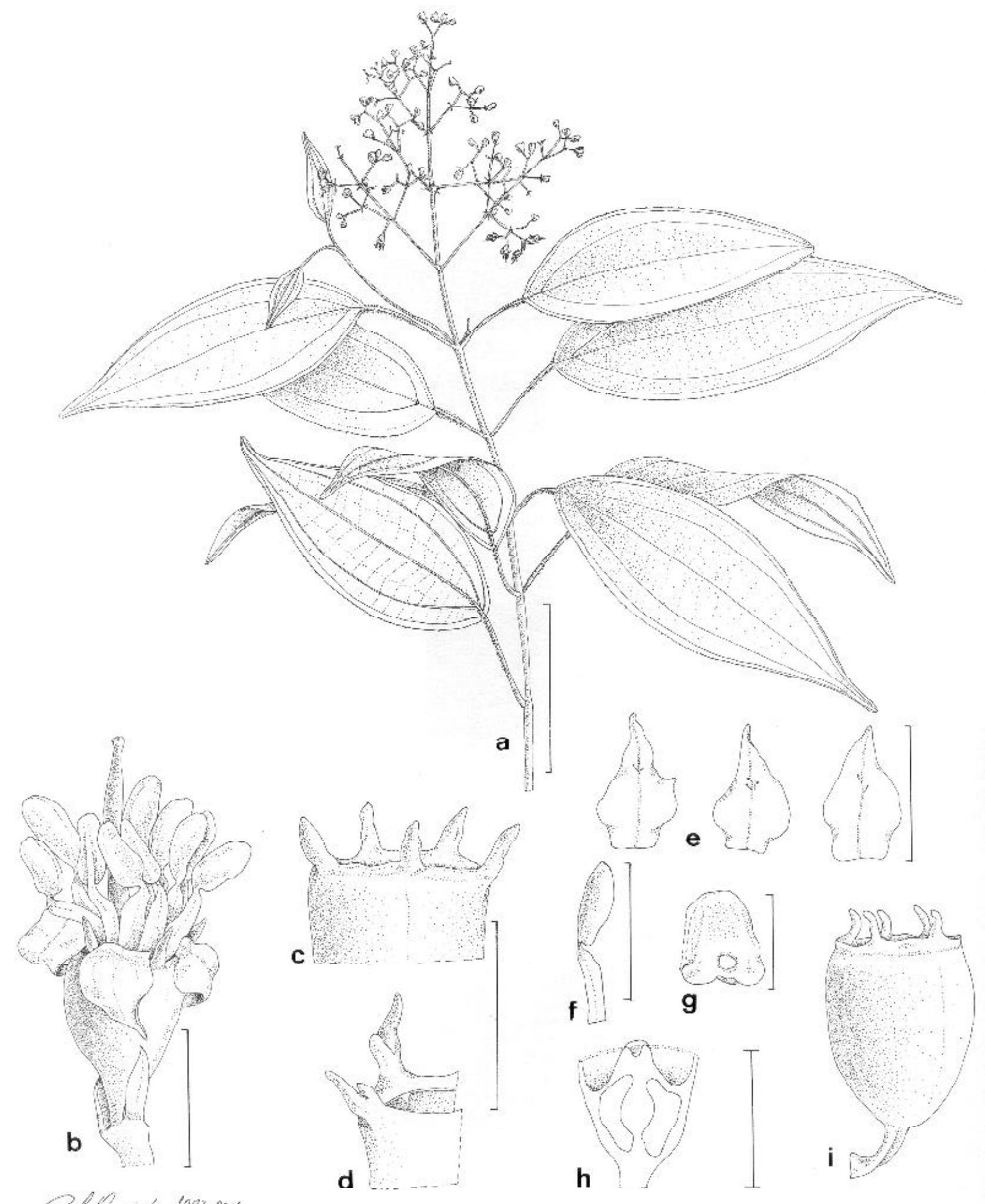

Figura 2. Leandra mattosii Baumgratz \& D’El Rei Souza (J. Mattos \& N. Mattos 14260; figura d: M. Kuhlmann 5036): a. Detalhe do ramo florífero. b. Flor. c. Detalhe do ápice do hipanto e cálice, evidenciando as lacínias aparentemente unilobadas. d. Detalhe das lacínias do cálice, visualizando-se a porção apical da lacínia interna que foi deslocada manualmente. e. Pétalas: face adaxial. f. Estame. g. Detalhe do poro terminal da antera, em vista polar. h. Secção longitudinal do ovário, evidenciando a adnação parcial ao hipanto, lóculos e o prolongamento apical. i. Fruto jovem. (Escalas: $a=5 \mathrm{~cm}$; $b-f, h-i=2 \mathrm{~mm} ; \mathrm{g}=0,5 \mathrm{~mm}$ ). 
mente bilobado, com as lacínias externas gibosas, geralmente geniculadas, apiculadas. Já L. truncata distingue-se, principalmente, pelo cálice truncadoondulado, com as lacínias muito reduzidas e bilobadas.

\section{Agradecimentos}

À Dra. Graziela Maciel Barroso (in memoriam), do Instituto de Pesquisas Jardim Botânico do Rio de Janeiro, e ao Dr. Jorge Fontella Pereira, Museu Nacional/UFRJ, pela revisão das diagnoses latinas; aos curadores dos herbários, pelos empréstimos concedidos; ao Conselho Nacional de Desenvolvimento Científico e Tecnológico (CNPq), pela bolsa de Produtividade em Pesquisa concedida ao primeiro autor.

\section{Referências bibliográficas}

Baumgratz, J.F.A. 1985. Morfologia dos frutos e sementes de Melastomatáceas brasileiras. Arquivos do Jardim Botânico do Rio Janeiro 27: 113-155.

Cogniaux, A. 1886. Leandra Raddi (Melastomataceae). In: C.F.P. Martius \& A.G. Eichler (eds.). Flora Brasiliensis. Monachii, Lipsiae Frid. Fleischer, v.14, pt. 4, p. 66-209, t. 17-44.

Cogniaux, A. 1891. Leandra Raddi (Melastomataceae). In: A. De Candolle \& C. De Candolle. Monographiae Phanerogamarum. Paris, G. Masson, v.7.

Judd, W.S. \& Skean Jr., J.D. 1991. Taxonomic studies in the Miconieae (Melastomataceae). IV. Generic realignments among terminal-flowered taxa. Bulletin of the Florida Museum of Natural History, Biological Sciences 36(2): 25-84.

Wurdack, J.J. 1962. Melastomataceae of Santa Catarina. Sellowia 14: 109-217. 